\title{
Role of Phosphodiesterase Enzyme Modulation in Protection of Hepatotoxicity Induced by D-Galactosamine in Rats
}

\author{
Magdy K. A. Hassan ${ }^{1}$, Mohamed A. El-Moselhy², Ashraf T. \\ Abu-Elwafa ${ }^{2}$, Hanaa M. Ibrahim ${ }^{1}$, and Aliaa F. Mohammed ${ }^{2}$ \\ ${ }^{1}$ Department of Physiology; ${ }^{2}$ Pharmacology \& Toxicology \\ Faculty of Pharmacy, Minia University
}

\begin{abstract}
The study was conducted to investigate possible mechanisms of the hepatoprotective actions of Pentoxifylline (a non-selective phosphodiesterase inhibitor) against experimentally induced hepatic injury in rats. The rats were randomly assigned to vehicle (saline), pentoxifylline (PTX, $100 \mathrm{mg} / \mathrm{Kg}$ ) and silymarin (SYM, $100 \mathrm{mg} / \mathrm{Kg}$ ) and combination of the two in the same doses pretreated groups for three weeks, in addition to the control group. Hepatic injury was induced by intraperitoneal single dose injection of D-galactosamine (D-GAL, 800mglkg). Hepatic functions parameters (serum levels of albumin, and alkaline phosphatase (ALP) activity were determined. Antioxidants properties of pentoxyphylline were examined via measuring the antioxidant enzymes activities such as superoxide dismutase (SOD), catalase (CAT), lipid peroxides as well as hepatic total nitrites. Histopathological findings were, also, determined using portions of liver tissues. Results showed that the liver injury induced by D-galactosamine treated rats was improved in the three pretreated groups to variable extents. Pretreatment with PTX prevented D-galactosamine induced reduction of antioxidative enzymes, SOD and CAT, and attenuated the elevated MDA level in hepatic tissue which was observed in non pretreated D-Gal group. These findings could be attributed to antioxidant activity of PTX and its metabolites effects. It 'also' caused increase in hepatic triglycerides, normalization of nitric oxide level, and lowering serum ALP activity and inhibited reduction of serum albumin level caused by D-Gal, these effects reflect possible hepatoprotective effects of PTX.
\end{abstract}

\section{INTRODUCTION}

Because liver is located between the absorptive surface of the gastrointestinal tract and drug targets throughout the body, so it is central to the metabolism of virtually every foreign substance. Liver injury can be caused by different agents, such as viruses, chemicals, alcohol, and autoimmune diseases ${ }^{\left({ }^{1}\right)}$.
D-Gal is a well established hepatotoxicant, it induces a diffuse type of liver injury closely resembling human viral hepatitis and acute, selflimiting hepatitis with necrosis, inflammation and regeneration, resembling a drug-induced disease in humans ${ }^{(2)}$. The toxicity of D-Gal is mainly related to the depletion of uridine pools that are associated with limited ribonucleic acid (RNA) and 
protein synthesis, thus altering hepatocellular function ${ }^{(3)}$.

Different pharmacological compounds have been tested to reduce acute or chronic inflammatory responses, which may damage liver function. It was demonstrated in pervious studies that phosphodiesterase inhibitors may be protective in various liver injury models ${ }^{(4,5)}$.

PTX

(non-selective phosphodiesterase inhibitor) is a methyl xanthine derivative that has been used for its regulatory effect on blood flow. PTX increases the flexibility of red and white blood cells, reduces the blood viscosity by decreasing plasma fibrinogen concentrations and decrease platelet aggregation and thrombus formation. Polymorphonuclear leukocytemediated effects, such as superoxide production, chemotaxis, phagocytosis and tumor necrosis factor (TNF) production are inhibited by pentoxifylline ${ }^{(6)}$.

Silymarin (SYM) from milk thistle is a hepatoprotective drug was widely used in the world. Silymarin may reduce free radical production and lipid peroxidation in the setting of hepatotoxicity as it has powerful antioxidant property ${ }^{(7)}$. Silymarin may act through its ability for toxin blockade, it may bind to the hepatocyte cell membrane receptor site, inhibiting binding of toxins to these sites ${ }^{(8)}$

The aim of the present study was to test the possible hepatoprotective effects of PTX on hepatotoxicity induced by D-Gal and the possible mechanisms underlying that protection, as a sole effect or synergistic with silymarin.

\section{MATERIAL \& METHODS}

\section{Animals:}

Animals used in the present study were male albino rats ( 8 weeks of age) weighing 180-200 g. Animals were supplied by National Research Center, Giza. They were kept under constant environmental conditions throughout the period of the experiment. Animals were exposed to dark/light cycle of 12:12 hours

\section{Experimental procedures:}

After the acclimatization period, the rats were divided into five groups, each of 12 rats. All animals were fed standard animal chow along the period of the experiment (21 days). (1) Control group; in which animals received saline $0.5 \mathrm{ml} /$ day i.p. for 3 weeks. (2) Control treated group; in which animals received saline 0.5 $\mathrm{ml} /$ day i.p. for 3 weeks and at $21^{\text {st }}$ day received a single dose of Dgalactosamine. (3) PTX treated group; in which animals received PTX (100mg $\backslash \mathrm{kg} \backslash$ day, i.p.) dissolved in 0.5 $\mathrm{ml}$ saline for 3 weeks. (4) Silymarin treated group; in which animals received Silymarin (100mg $\backslash \mathrm{kg} \backslash$ day, oral) suspended in $0.5 \mathrm{ml} 0.1 \%$ starch solution for 3 weeks. (5) PTX +Silymarin group; in which animals received pentoxifylline followed by simultaneous administration of Silymarin for 3 weeks by the same previous doses. These doses were selected on the basis of previous studies $(\mathbf{9 , 1 0 )}$.

All groups except group 1 received at $21^{\text {st }}$ day a single dose of Dgalactosamine $(800 \mathrm{mg} \backslash \mathrm{kg}$, i.p.) once 
in the morning. At the end of the study, the animals were sacrificed and blood was collected for separation of sera. The livers were isolated, washed off blood and connective tissue was removed then portions of liver tissues were separated and kept in 10\% formalin for histopathological examination.

Immediately, the rest of liver tissues were immediately flash-frozen in liquid nitrogen and stored at $-80^{\circ} \mathrm{C}$. Kits used for determination of MDA (Biodiagnostic, Egypt) as a marker of lipid peroxides ${ }^{(\mathbf{1 1})}$, tissue nitrite as an indicator of nitric oxide (Biodiagnostic, Egypt), albumin (dp International, Egypt), ALP, and total protein concentrations (Spectrum Diagnostics, Egypt), SOD (12), and CAT enzymes (13) (Biodiagnostic, Egypt). The measurements were done according to instructions illustrated in the kits. In addition, serum albumin levels and ALP activities were measured in sera of all the experimental animals.

\section{Histopathological analysis:}

Small pieces of the livers fixed in $10 \%$ buffered neutral formalin were processed for embedding in paraffin. Sections of 5-6 $\mathrm{mm}$ thickness were stained with hematoxylin and eosin, examined for histopathological changes ${ }^{(14)}$.

\section{Statistical Analysis of the Data:}

Results were expressed as means \pm standard error of the mean (SEM) and were analyzed for statistically significant difference using one-way analysis of variance (ANOVA) followed by the Tukey-Kramar post analysis test. $\mathrm{P}$ values less than 0.05 were considered significant.

\section{RESULTS}

Figure (1) shows that D-Gal caused a significant reduction of serum albumin level when compared to control rats. The serum albumin level was $2.132 \pm 0.125 \mathrm{~g} / \mathrm{dl}$ in D-Gal group compared to $3.308 \pm 0.163 \mathrm{~g} / \mathrm{dl}$ in control group. PTX significantly increased serum albumin level to 3.103 $\pm 0.184 \mathrm{~g} / \mathrm{dl}$ compared to nonpretreated D-Gal group. Meanwhile, SYM and PTX+SYM significantly increased serum albumin level $(3.130 \pm$ $0.087 \mathrm{~g} / \mathrm{dl}$ and $3.199 \pm 0.107 \mathrm{~g} / \mathrm{dl}$ for SYM and PTX+SYM respectively compared to non-pretreated D-Gal group).

Figure (2) illustrates that administration of D-Gal caused a significant elevation of serum ALP activities when compared to control rats $(633.50 \pm 41.33 \mathrm{IU} / \mathrm{L}$ in $\mathrm{D}-\mathrm{Gal}$ group compared to $331.50 \pm 28.38$ IU/1 in control group). Administration of D-Gal to pretreated rats with PTX or SYM significantly decreased serum ALP activities compared to nonpretreated D-Gal group (the serum ALP were $364.40 \pm 23.71 \mathrm{IU} / 1$ and $349.30 \pm 33.66 \mathrm{IU} / 1$, for PTX and SYM respectively). In addition, concomitant administration of PTX and SYM before D-Gal administration, significantly decreased serum ALP activities compared to non-pretreated D-Gal group (412.40 \pm $72.56 \mathrm{IU} / \mathrm{I})$.

Figure (3) illustrates that D-Gal caused a significant decrease of CAT activity when compared to control rats $(0.131 \pm 0.004 \mathrm{U} / \mathrm{mg}$ tissue protein in $\mathrm{D}-\mathrm{Gal}$ group compared to $0.210 \pm$ $0.016 \mathrm{U} / \mathrm{mg}$ tissue proteins in control group). Pretreatment with PTX or 
SYM significantly increased CAT activity of liver tissue compared to non-pretreated D-Gal group (0.199 \pm $0.012 \mathrm{U} / \mathrm{mg}$ tissue protein and $0.172 \pm$ $0.004 \mathrm{U} / \mathrm{mg}$ tissue protein, for PTX and SYM respectively). Combined administration of PTX and SYM significantly increased CAT activity of liver tissue when compared to nonpretreated D-Gal group $(0.181 \pm 0.008$ $\mathrm{U} / \mathrm{mg}$ tissue proteins).

Figure(4) illustrates the activity of superoxide dismutase was significantly reduced in D-Gal group when compared to control rats (122.80 $\pm 16.38 \mathrm{U} / \mathrm{mg}$ tissue protein in D-Gal group compared to $175 \pm 11.40 \mathrm{U} / \mathrm{mg}$ tissue protein in control group). In PTX pretreated group, a significant increase of supreroxide dismutase activity was noticed compared to nonpretreated D-Gal group (163.20 \pm 4.72 $\mathrm{U} / \mathrm{mg}$ tissue protein). Meanwhile, pretreatment with silymarin or $(\mathrm{PTX}+$ SYM) significantly increased supreroxide dismutase activity when compared to non-pretreated D-Gal group $(187.40 \pm 4.35 \mathrm{U} / \mathrm{mg}$ tissue protein and $176.90 \pm 10.23 \mathrm{U} / \mathrm{mg}$ tissue protein, for silymarin and PTX + SYM respectively)

Figure (5) illustrates that intraperitoneal administration of Dgalactosamine significantly elevated the hepatic tissue malondialdehyde (MDA) concentration to about two folds the value observed for control group, reaching a value of $1.538 \pm$ $0.109 \mathrm{nmol} \mathrm{MDA} / \mathrm{g}$ tissue proteins as compared to $0.753 \pm 0.055 \mathrm{nmol}$ $\mathrm{MDA} / \mathrm{g}$ tissue protein for the control group. D-Gal induced elevation of hepatic thiobarbituric acid reactive species (TBARs) as a measure of lipid peroxidation was significantly reversed in rats pretreated with PTX, SYM or their combination $(0.934 \pm$ $0.081,0.955 \pm 0.014$ and $1.034 \pm$ $0.081 \mathrm{nmol} \mathrm{MDA} / \mathrm{g}$ tissue proteins for PTX, SYM and PTX + SYM pretreated groups, respectively).

Figure (6) shows that the level of hepatic total nitrites in Dgalactosamine treated groups was significantly increased compared to the control group $(1.733 \pm 0.142 \mathrm{nmol}$ $/ \mathrm{g}$ tissue protein and $0.885 \pm 0.080$ $\mathrm{nmol} / \mathrm{g}$ tissue protein for D-GAL and control groups, respectively). PTX significantly decreased hepatic total nitrites concentration $(0.910 \pm 0.073$ $\mathrm{nmol} / \mathrm{g}$ protein tissue) compared to non-pretreated D-Gal group. SYM as well as (PTX + SYM) pretreated groups significantly decreased the level of hepatic total nitrites (1.061土 0.08 and $1.082 \pm 0.091 \mathrm{nmol} / \mathrm{g}$ protein tissue for SYM and PTX+SYM respectively) when compared to nonpretreated D-Gal group.

Histopathological findings of the effects of D-galactosamine on liver in normal rats and rats pretreated with Pentoxifylline, Silymarin and their combination:

In the control group (group1) the liver was normal with no evidence of any microscopic abnormalities (Fig 7 ), in control treated group (D-GAL group 2); microscopically, vasculitis, represented by congested blood vessels and perivascular edema and few lymphocytes infiltrations was noticed. Thickening and hyalinization of the tunica media of hepatic arterioles were observed (Fig 8). The collagen, produced by the fibroblasts, was stained red by Van Gieson's stain (Fig 9). Other portal areas were infiltrated with round cells 
(lymphocytes and macrophages) and few esinophils. The latter were focally invaded and gradually replaced the hepatic parenchyma (Fig 10). Extravasated erythrocytes were rarely observed among the hepatocytes. Periportal fatty change was also seen. In PTX group (group 3), Microscopically, Some portal areas showed congested blood vessels and leukocyte margination and emigration besides mild hyperplasia of the epithelial lining of the bile ducts and few round cell infiltrations (Fig 11). In SYM group (group 4); microscopically, the liver revealed small areas of coagulative necrosis (Fig 12). Few round cells (mainly of lymphocytes) in the portal areas and the interstitial tissue were detected (Fig 13), in PTX+SYM group (group 4) microscopically, the liver revealed slight vacuolations inside the cytoplasm of the hepatocytes (Fig 14).

Figure (1): Effect of D-galactosamine on serum albumin level in normal rats and rats pretreated with pentoxifylline, silymarin and their combination

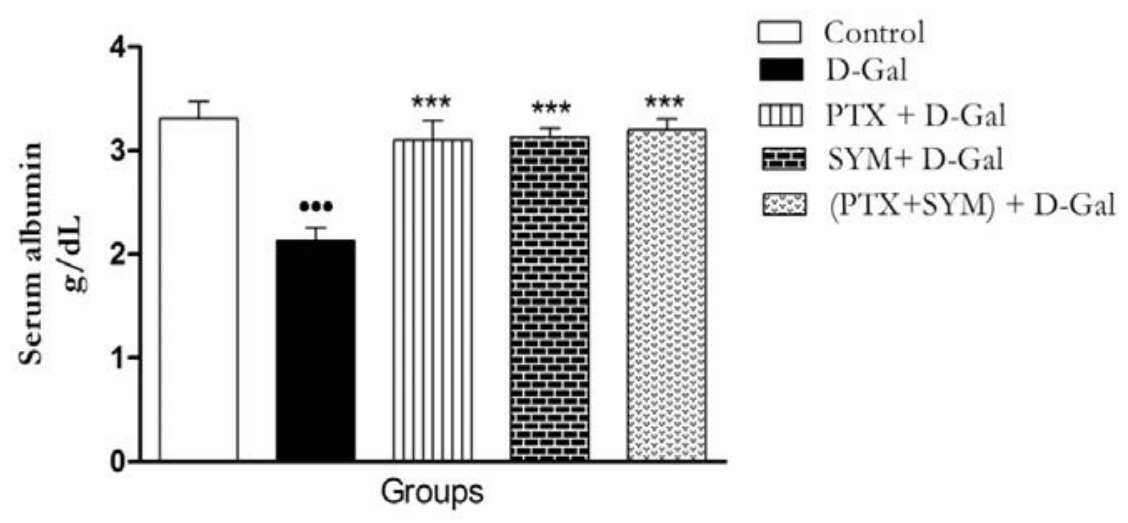


Figure (2): Effect of D-galactosamine on serum alkaline phosphatase in normal rats and rats pretreated with pentoxifylline, silymarin and their combination

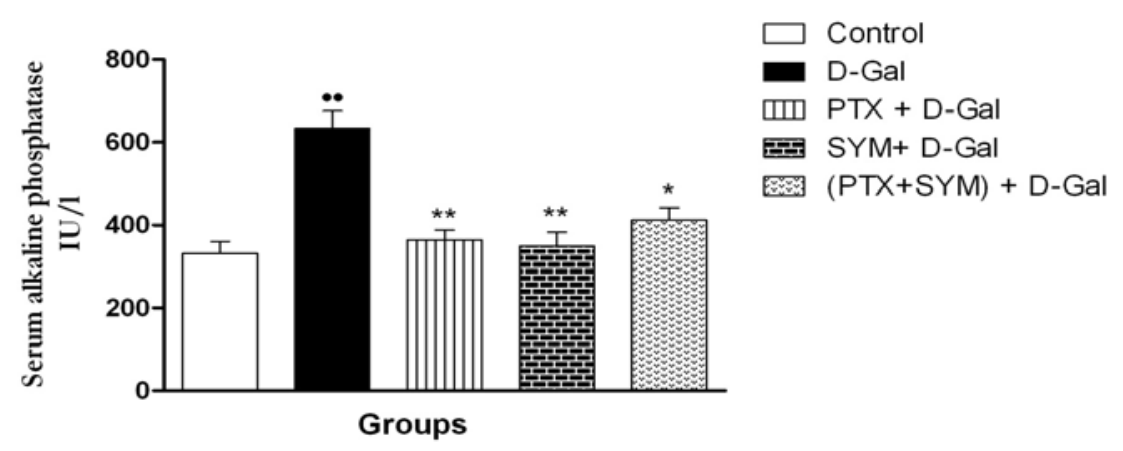

Values represent the mean \pm S.E of 6 observations.

$\bullet$ significantly different from control group at $\mathrm{P}<0.01$.

$\cdots$ significantly different from control group at $\mathrm{P}<0.001$.

"significantly different from D-Gal group at $\mathrm{P}<0.05$.

** significantly different from D-Gal group at $\mathrm{P}<0.01$.

s** significantly different from $\mathrm{D}-$ Gal group at $\mathrm{P}<0.001$.

Figure(3): Effect of D-galactosamine on catalase activity of liver tissue in normal rats and rats pretreated with pentoxifylline, silymarin and their combination

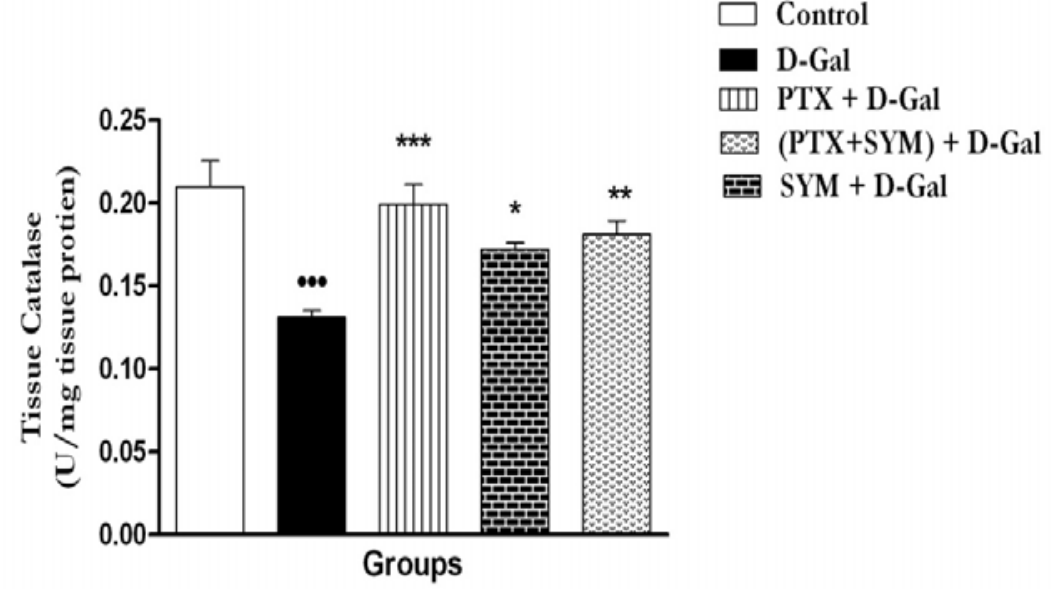


Figure (4): Effect of D-galactosamine on superoxide dismutase activity of liver tissue in normal rats and rats pretreated with pentoxifylline, silymarin and their combination

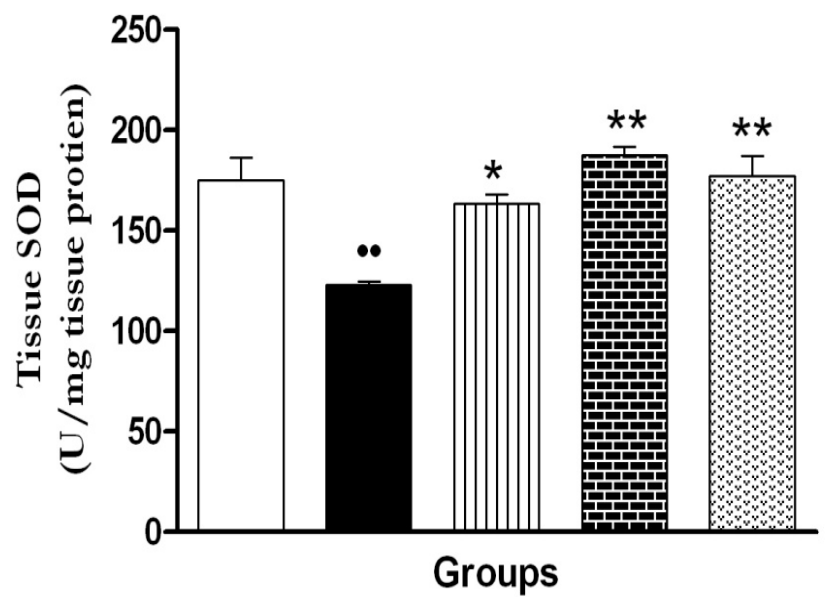

Control

D-Gal

Шा PTX + D-Gal

폴 $\mathrm{SY}+\mathrm{D}-\mathrm{Gal}$

ए:

Values represent the mean \pm S.E of 6 observations.

$\bullet$ significantly different from control group at $\mathrm{P}<0.01$.

- significantly different from control group at $\mathrm{P}<0.001$.

"significantly different from $\mathrm{D}-\mathrm{Gal}$ group at $\mathrm{P}<0.05$.

** significantly different from D-Gal group at $\mathrm{P}<0.01$.

significantly different from $\mathrm{D}-\mathrm{Gal}$ group at $\mathrm{P}<0.001$

Figure (5): Effect of D-galactosamine on hepatic lipid peroxidation in normal rats and rats pretreated with pentoxifylline, silymarin and their combination

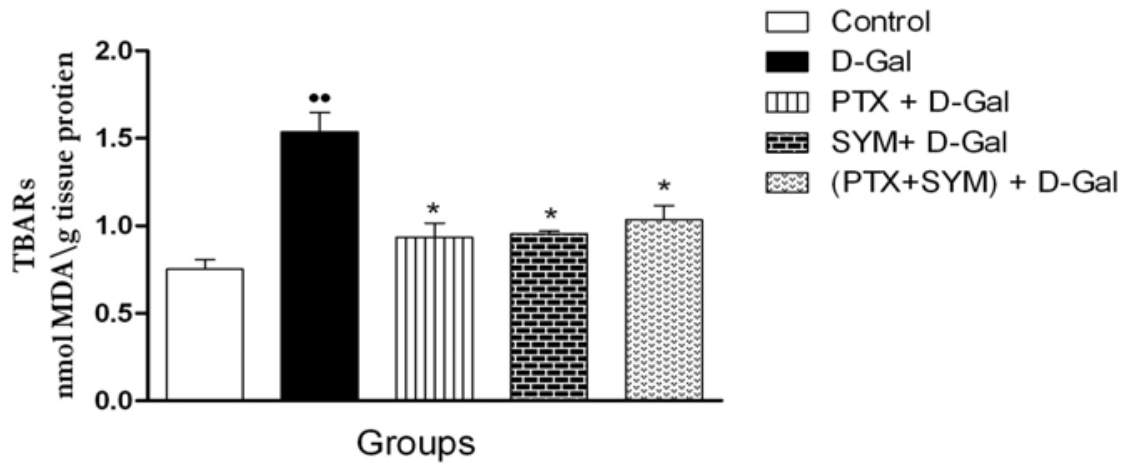


Figure (6): Effect of D-galactosamine on hepatic total nitrites in normal rats and rats pretreated with pentoxifylline, silymarin and their combination

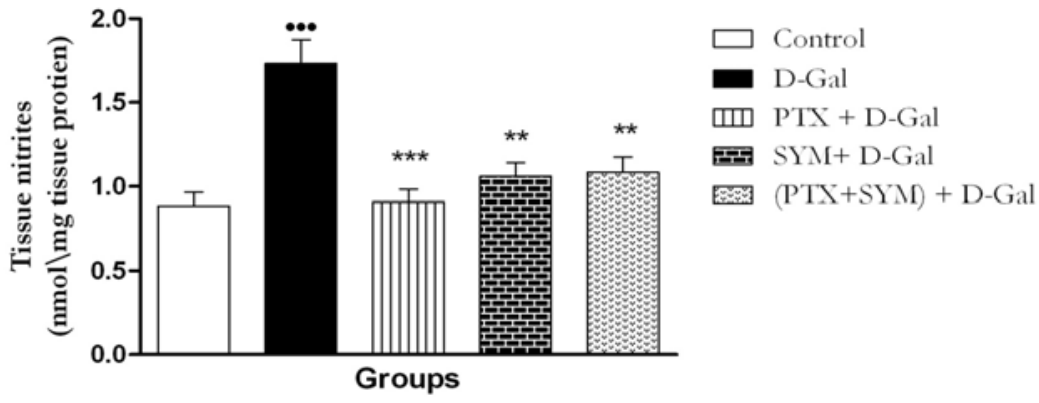

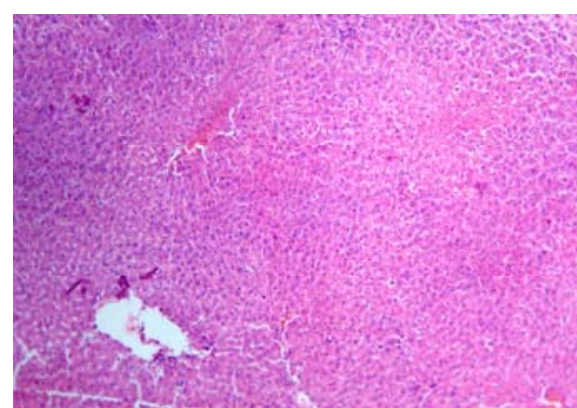

Fig (7): Liver of gp (1) showing normal parenchymal and sinusoidal structures, $\mathrm{H} \& \mathrm{E}$.

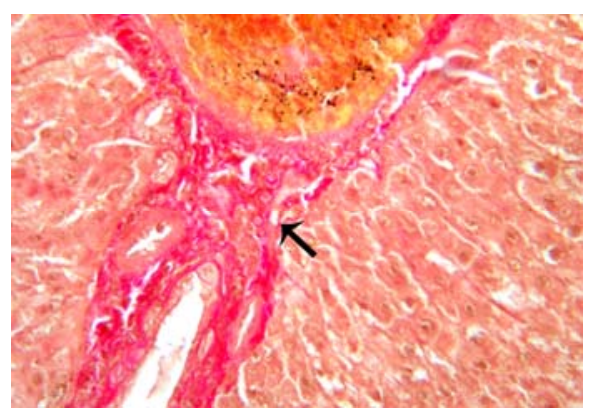

Fig (9): Liver of gp (2) showing collagen fibers stained red (arrow) by Van Gieson's stain x 300

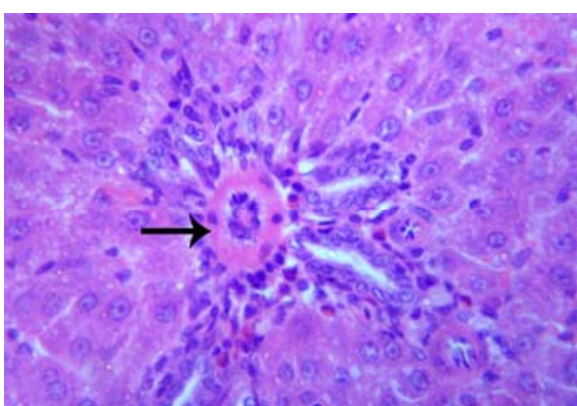

Fig (8): Liver of gp (2) showing portal area with thickening and hyalinization of the tunica media of hepatic arteriole (arrow), H\&E. x 500.

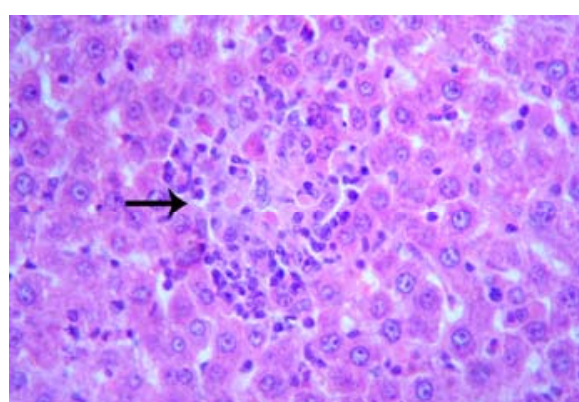

Fig (10): Liver of gp (2) showing lymphocytes, macrophages and few esinophils replacing the hepatic parenchyma (arrow), H\&E. x 500. 


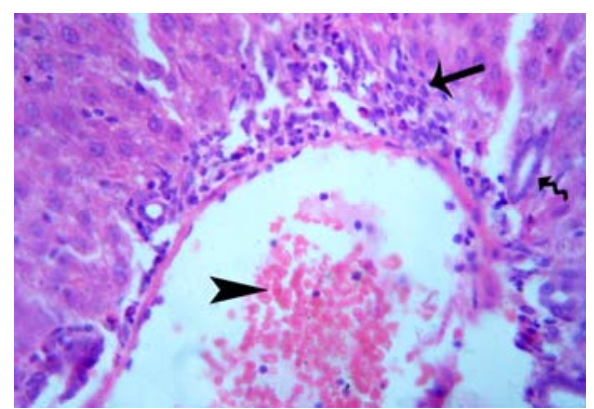

Fig (11): Liver of gp (3) showing portal area with congested blood vessel (arrow head) and few round cell infiltrations (arrow), HE x 300

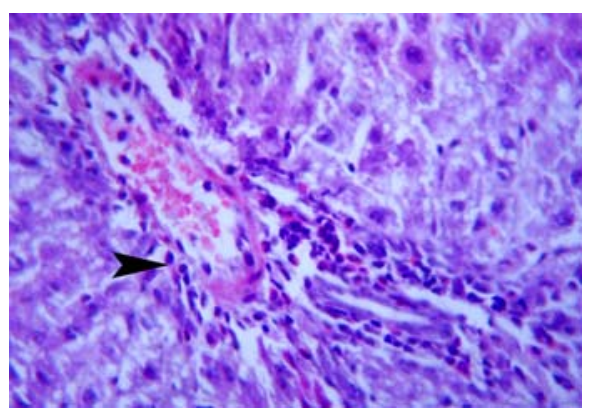

Fig (13): Liver of gp (4) showing portal area with few round cell infiltrations (arrow head), HE x 300.

\section{DISCUSSION}

The present investigation was an attempt to investigate the protective effects of PTX on experimentally induced hepatic toxicity. Hepatic injury in the study was induced by using a single dose of D-Gal, which is a hepatotoxicant, and inducer in hepatic injury models, both in vivo and in vitro. In vivo, D-Gal causes hepatic damage resembling viral hepatitis and drug induced hepatitis $^{(15)}$.

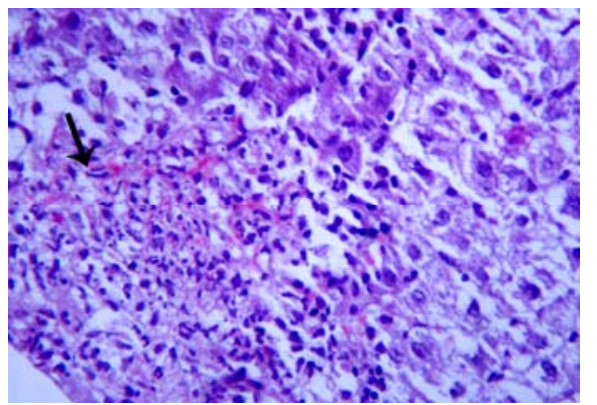

Fig (12): Liver of gp (4) showing small area of coagulative necrosis (arrow), HE x 300 .

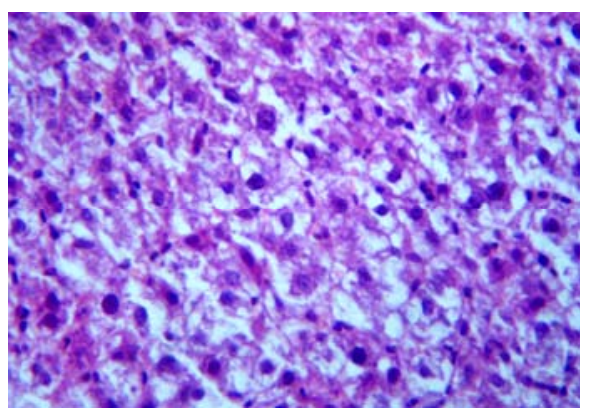

Fig (14): Liver of gp (5) showing, vacuolations inside the cytoplasm of hepatocytes HE x 300 .

SYM was used in the present study as a reference and a wellestablished hepatoprotective agent. This compound has been demonstrated to posse hepatoprotectve properties in both in vitro $^{(16)}$ and in vivo ${ }^{(17)}$ studies. SYM proved to be protective against several hepatotoxicants such as carbon tetrachloride ${ }^{(\mathbf{1 8})}$, paracetamol ${ }^{(19)}$ and D-galactosamine ${ }^{(\mathbf{2 0})}$ in different animal models.

The current study showed that DGal caused a significant decrease in serum albumin level as an indicator 
for the hepatotoxicity, which is a direct effect of D-Gal in the liver. This result agreed with results that obtained by Wong et al. (21). In addition, Dabeva and Shafritz ${ }^{(22)}$ attributed the lowering of serum albumin level to the reduction of albumin mRNA expression, they observed that there was an abrupt decrease of albumin mRNA which was maximum at the day two after D-Gal administration.

The present data showed that pretreatment with PTX significantly inhibited the reduction in serum albumin in D-Gal treated rats compared to control rats. This effect may be due to the increase in blood flow to liver and irrigation of liver which, might help in returning liver vitality. The same effect of PTX on serum albumin level was previously reported by Peterson ${ }^{(23)}$

D-Gal caused an increased serum ALP compared to non-treated control group. This rise in serum ALP activity in rats may be attributed to the disturbance in the secretory activity or in the transport of metabolites or may be due to altered synthesis of certain enzymes as in other hepatotoxic conditions ${ }^{(24)}$.

The present result is in accordance with the result of Yoo et al. ${ }^{(15)}$ who observed an increase of ALP in D-Gal treated group. The work of Abdel Salam and his cooperators ${ }^{(30)}$ also reported an increase of ALP activity in carbon tetrachloride $\left(\mathrm{CCl}_{4}\right)$ and acetaminophen models of liver injury. Serum ALP activity in PTX pretreated group was returned to approximately its normal level compared to D-Gal treated group. This effect, also, was comparable to the effect of SYM on ALP activity in serum, and this finding is in agreement with that of Peterson.

However, PTX has been reported that, it had no effect on serum ALP activity as described by Abdel Salam and his colleagues ${ }^{(25)}$ who worked on bile duct-obstructed rats as a model of hepatic toxicity. This difference in the two results may be attributed to the difference utilized models of hepatic injury. We suggest that the bile ductobstruction may cause more pronounced elevation in ALP activity as ALP is mainly produced in bile duct and its release is enhanced by cholestasis. Thus, PTX failed in preventing that effect.

In the current work, administration of single dose of D-Gal caused non significant decrease in triglycerides concentration in the liver, this effect may be due to impairment of hepatic synthesis of triglycerides. Kattermann and Sirowej (26) demonstrated that such decrease could be contributed to sex differences in the fatty liver induced by D-Gal, and the level of hepatic triglycerides content decreased especially in male animals rather than females where the triglycerides accumulation on liver was $75 \mathrm{mg} / \mathrm{g}$ in female animals while male animals showed only $33 \mathrm{mg} / \mathrm{g}$.

In the present work, a single intraperitoneal administration of DGal resulted in a significant reduction of tissue catalase and superoxide dismutase activity in addition to elevated level of thiobarbituric acid reactive species (TBARs) as a biochemical marker of lipid peroxidation. It has been suggested that oxygen derived free radicals released from activated hepatic macrophages are the primary cause of 
D-Gal induced liver damage ${ }^{(27)}$. Also, the increasing production of oxygen derived free radicals has been reported in primary culture of rat hepatocyte damage induced by D-Gal in the study of Quintero and his associates ${ }^{(28)}$.

The lowering of SOD activity and elevated MDA levels were previously reported by Gao and Zhou ${ }^{(29)}$ who induced liver injury by administration of D-Gal $(500 \mathrm{mg} / \mathrm{kg})$ to mice. On the other hand, Wong et al. ${ }^{\text {(21) }}$ reported an increase in SOD activity which contradicts the present results. They speculated that the up-regulation of SOD activity may be attributed to adaptive mechanisms to counteract increased oxidative stress.

There are several studies reporting the relevance of catalase to hepatic fibrosis i.e. catalase blocked Tumor Growth Factor B1 (TGF-B1) and collagen production in hepatic stellate cells ${ }^{(30)}$. CAT activity was reduced in human hepatic injury and cirrhosis ${ }^{(31)}$ and over-expression of CAT rescued hepatic damage. A possible explanation of the effect of D-Gal on CAT activity is the assumption that the impairment of CAT activity might be the cause rather than a consequence of D-Gal hepatotoxicity. Thus, the increase in oxidative stress caused by impaired CAT activity is likely a key element of triggering hepatic fibrosis. This is in agreement with the reported effect of thioacetamide (another hepatotoxic agent) on catalase activity $^{(32)}$. The reduction of CAT activity observed in D-Gal treated group in the study was, also, reported in pervious studies ${ }^{(33)}$.

The work, pretreatment with PTX prevented D-Gal induced reduction of antioxidative enzymes, SOD and CAT and attenuated the elevated MDA level in hepatic tissue, which observed in control group. This effect may be due to increased blood flow to liver which increases its antioxidant capacity in addition of direct antioxidant effect of PTX and its metabolites.

As Silymarin has strong antioxidative properties and is able to scavenge both free radicals and reactive oxygen species, so it exhibited the same results observed with PTX pretreated group.

Another possible explanation for the antioxidant activity of PTX is likely attributed to inhibition of phosphodiesterase and increase of cyclic adenosine monophosphate (cAMP) as well as cyclic guanosine monophosphate (cGMP) levels by PTX [6]. There is good evidence that cyclic nucleotides are able to prevent oxidative stress by reduction of lipid peroxidation $^{(34)}$.

Demir and Inal-Erden (35) explained the effects of PTX on production of free radicals to be linked with leukocyte-driven radicals. PTX can enhance the chemotactic response of neutrophils. PTX, also, may inhibit the phagocytosis and superoxide production by neutrophils and monocytes. PTX showed protective effects against the free radical damage in previous studies that reported by Desmouliere et al. ${ }^{(36)}$ and Sener et al. ${ }^{(37)}$. They used model of intestinal ischemia/reperfusion injury to evaluate these effects.

Savas et al. ${ }^{(38)}$ reported that PTX reduced levels of MDA as well as SOD and CAT activities in a rabbit model of ischemia-reperfusion injury, they attributed these effects to their 
assumption that PTX is a free radical scavenger and neutrophils stabilizer. Thus, PTX decreases free radical production, antioxidant enzymes and cytokines released from the activated neutrophils.

Nitric oxide plays a role in proinflammatory cell signaling, altering cellular gene expression, enzyme activity and transcription factor activity. In addition, NO regulates vasodilatation, platelets and neutrophils aggregation, and local organ blood flow. Therefore, NO influences cell and tissue function. The present study revealed that D-Gal induced hepatic injury was associated with elevated NO level. However, the role of NO in the liver is controversial because liver toxicity as well as liver protection have been attributed to $\mathrm{NO}^{(39)}$

The current study reported that the inhibition of inducible nitric oxide synthase (iNOS) reduced D-Gal induced apoptosis in primary culture of rat hepatocytes. Furthermore, other studies found that NO scavengers may potentially reduce toxicity from excessive iNOS activity in a model of liver injury induced by hemorrhagic shock $^{(40)}$.

On the other hand, it has been shown that administration of $\mathrm{NO}$ donors provides cytoprotection from inflammatory liver damage and hepatocellular apoptosis ${ }^{(41)}$. However, pharmacological blockade of iNOS either aggravates or attenuates liver injury or is ineffective ${ }^{(39)}$.

Interestingly, the present results showed that PTX as well as SYM reduced the total level of nitrate/nitrite (the stable metabolite of NO). Such reduction was significant compared to results of non pretreated D-Gal group. This effect may be attributed to the fact that PTX attenuates the expression of inducible NO synthase. The reduction of expression in iNOS mRNA by PTX may result from the reduced recruitment and/or activation of NO producing inflammatory cells. Therefore, it is reasonable to expect that the beneficial impact of PTX treatment is likely due to modulation of iNOS pathway ${ }^{(42)}$.

In conclusion, the present data suggest that PTX produced protective effects against the disturbed biochemical markers and histopathological findings of D-Gal induced hepatotoxicity in rat model. It is well established that PTX increases cAMP which has been associated with inhibition of macrophage function and this decreasing in Kupffer cell function protects against hepatic injury. PTX, also, improved blood flow in tissues so, it helps in liver perfusion with blood, oxygen and nutrients. In addition, PTX reduced the levels of toxic free radical and attenuated NO production.

Our biochemical data were reflected on the structural and histopathological findings, could confirming the hepatoprotective effect of PTX. Taken together, the data suggest that PTX act as a promising hepatoprotective agent and that effect is mediated via its antioxidant properties.

\section{REFERENCES}

1. Sugiyama, K., He, P., Wada, S., and Saeki S. (1999):Teas and other beverages suppress Dgalactosamine-induced liver 
injury in rats. J. Nutr., 129(7): 1361-7.

2. Jonker, A.M., Dijkhuis, W.J., Boes, A., Hardonk, M.J., and Grond, J. (1992): Immunohistochemical study of extracellular matrix in acute galactosamine hepatitis in rats. Hepatology, 15(3):423-31.

3. Keppler, D.O., Pausch, J. and Decker, K. (1974):Selective uridine triphosphate deficiency induced by D-galactosamine in liver and reversed by pyrimidine nucleotide precursors. Effect on ribonucleic acid synthesis. J. Biol. Chem., 249(1):211-6.

4. Fischer, W., Schudt, C., and Wendel, A. (1993): Protection by phosphodiesterase inhibitors against endotoxin-induced liver injury in galactosaminesensitized mice. Biochem. Pharmacol., 45(12):2399-404.

5. Taguchi, I., Oka, K., Kitamura K., Sugiura M., Oku, A., and Matsumoto M. (1993): Protection by a cyclic AMPspecific phosphodiesterase inhibitor, rolipram, and dibutyryl cyclic AMP against Propionibacterium acnes and lipopolysaccharide-induced mouse hepatitis. Inflamm. Res., $\mathrm{x} 48(7): 380-5$.

6. Thompson, M.K., Tuma, R.F., and Young, W.F.(1999):The effects of pentoxifylline on spinal cord blood flow after experimental spinal cord injury. J. Assoc. Acad. Minor Physiol., 10(1):23-6.

7. Feher, J., Lang I., Nekam, K., Gergely, P., and Muzes G. (1990): In vivo effect of free radical scavenger hepatoprotective agents on superoxide dismutase (SOD) activity in patients. Tokai J. Exp. Clin. Med., 15(2-3):129-34.

8. Faulstich, H., Jahn, W. and Wieland, T. (1980): Silybin inhibition of amatoxin uptake in the perfused rat liver. Arzneimittelforschung, 30(3):452-4.

9. Wang, X. and Cederbaum, A.I. (2007):Acute ethanol pretreatment increases FASmediated liver injury in mice: role of oxidative stress and CYP2E1-dependent and independent pathways. Free Radic. Biol. Med., 42(7): 971-84.

10. Copple, B.L., Ganey, P.E. and Roth, R.A. (2003):Liver inflammation during monocrotaline hepatotoxicity. Toxicology, 190(3):155-69.

11. Buege, J.A. and Aust, S.D. (1978):Microsomal lipid peroxidation. Methods Enzymol., 52:302-10.

12. Nishikimi, M., Appaji, N., and Yagi, K. (1972): The occurrence of superoxide anion in the reaction of reduced phenazine methosulfate and molecular oxygen. Biochem. Biophys. Res. Commun., 46(2):849-54.

13. Aebi, H. (1984): Catalase in vitro. Methods Enzymol., 105:121-6.

14. Lin, C.C., Shieh, D.E., and Yen, M.H. (1997):Hepatoprotective effect of the fractions of Ban-zhilian on experimental liver injuries in rats. J. Ethnopharmacol., 56(3):193-200.

15. Yoo, Y.M., Nam, J.H., Kim, M.Y., Choi, J., and Park H.J.(2008): Pectolinarin and Pectolinarigenin of Cirsium setidens Prevent the Hepatic 
Injury in Rats Caused by DGalactosamine via an Antioxidant Mechanism. Biol. Pharm. Bull., 31(4):760-4.

16. Sonnenbichler, J. and Zetl, I. (1986): Biochemical effects of the flavonolignane silibinin on RNA, protein and DNA synthesis in rat livers. Prog. Clin. Biol. Res., 213:319-31.

17. Kropacova, K., Misurova, E., and Hakova, H. (1998):Protective and therapeutic effect of silymarin on the development of latent liver damage. Radiats. Biol. Radioecol., 38(3):411-5.

18. Muriel, $P$. and Mourelle, $M$. (1990): Prevention by silymarin of membrane alterations in acute CCl4 liver damage. J. Appl. Toxicol., 10(4):275-9.

19. Chrungoo, V.J., Singh, K. and Singh, J. (1997):Silymarin mediated differential modulation of toxicity induced by carbon tetrachloride, paracetamol and D-galactosamine in freshly isolated rat hepatocytes. Indian J. Exp. Biol., 35(6):611-7.

20. Keppler, D., Lesch, R., Reutter, W., and Decker, K. (1968): Experimental hepatitis induced by D-galactosamine. Exp. Mol. Pathol., 9(2): 279-90.

21. Wong, M.C., Portmann, B., Sherwood, R., Niemela, O., Koivisto H., Parkkila, S., Trick, K., Labbe, M.R., Wilson, J., Dash, P.R., Srirajaskanthan, R., Preedy, V.R., and Wiseman H. (2007): The cytoprotective effect of alpha-tocopherol and daidzein against $d$ galactosamine-induced oxidative damage in the rat liver. Metabolism, 56(7): 865-75.
22. Dabeva, M.D. and Shafritz, D.A. (1993):Activation, proliferation, and differentiation of progenitor cells into hepatocytes in the $D$ galactosamine model of liver regeneration. Am. J. Pathol., 143(6):1606-20.

23. Peterson,

T.C. (1993):Pentoxifylline prevents fibrosis in an animal model and inhibits platelet-derived growth factor-driven proliferation of fibroblasts. Hepatology, 17(3):486-93.

24. Kumar, P., Nagpaul, J.P., Singh, B., Bansal, R.C., and Sharma, R. (1978): Nature of inhibition of rat testicular alkaline phosphatase by Isatin. Experientia., 34(4):434-5.

25. Abdel Salam, O.M., Baiuomy, A.R., El-Shenawy, S.M., and Hassan, N.S. (2005): Effect of pentoxifylline on hepatic injury caused in the rat by the administration of carbon tetrachloride or acetaminophen. Pharmacol. Rep., 57(5):596-603.

26. Kattermann, R. and Sirowej, $\mathbf{H}$. (1979):Liver injury and lipid metabolism: sex differences in the fatty liver induced by $d$ galactosamine. Acta Hepatogastroenterol. (Stuttg)., 26(2):112-21.

27. Hu, H.L. and Chen, R.D. (1992): Changes in free radicals, trace elements, and neurophysiological function in rats with liver damage induced by D-galactosamine. Biol. Trace Elem. Res., 34(1):19-25.

28. Quintero, A., Pedraza, C.A., Siendones, E., Kamal El-Said A.M., Colell, A., Garcia-Ruiz, C., Montero, J.L., Delamata, 
M., Fernandez-checa, J.C., Mino, G., and Mutane, J. (2002):PGE1 protection against apoptosis induced by $D$ galactosamine is not related to the modulation of intracellular free radical production in primary culture of rat hepatocytes. Free Radic. Res., 36(3):345-55.

29. Gao, H. and Zhou, Y.W. (2005):Anti-lipid peroxidation and protection of liver mitochondria against injuries by picroside II. World J. Gastroenterol.,. 11(24):3671-4.

30. De Bleser, P.J., $\mathrm{Xu}$, G., Rombouts, K., Rogiers, V., and Geerts, A. (1999): Glutathione levels discriminate between oxidative stress and transforming growth factor-beta signaling in activated rat hepatic stellate cells. J. Biol. Chem., 274(48):33881-7.

31. Pastor, A., Collado, P.S., Almar, M., and GonzalezGallego, H. (1997): Antioxidant enzyme status in biliary obstructed rats: effects of $N$ acetylcysteine. J. Hepatol., 27(2):363-70.

32. Toyama, T., Nakamura, H., Harano, Y., Yamauchi, N., Morita, A., Kirishima, T., Minami, M., Itoh, Y., and Okanoue, T. (2004): PPARalpha ligands activate antioxidant enzymes and suppress hepatic fibrosis in rats. Biochem. Biophys. Res. Commun., 324(2):697-704.

33. Meena, B., Anbin Ezhilan, R., Rajesh, R., Sheik Hussain, A., Ganesan, B., and Anandan, R. (2008):Antihepatotoxic potential of Sargassum polycystum
(Phaeophyceae) on antioxidant defense status in $D$ galactosamine-induced hepatitis in rats. African Journal of Biochemistry Research, 2(2):051055 .

34. Abdollahi, M., Fooladian, F., Emami, B., Zafari, K., and Bahreini-Moqhadam, A. (2003):Protection by sildenafil and theophylline of lead acetateinduced oxidative stress in rat submandibular gland and saliva. Hum. Exp. Toxicol., 22(11):58792.

35. Schuppan D., Jia, J.D., Brinkhaus, B., and Hahn, E.G. (1999):Herbal products for liver diseases: a therapeutic challenge for the new millennium. Hepatology, 30(4):1099-104

36. Desmouliere, A., Xu, G., Costa, A.M., Yousef, I.M., Gabbiani, G., and Tuchweber, B. (1999):Effect of pentoxifylline on early proliferation and phenotypic modulation of fibrogenic cells in two rat models of liver fibrosis and on cultured hepatic stellate cells. J. Hepatol., 30(4):621-31.

37. Sener, G., Akgun, U., Satiroglu, H., Topaloglu, U., and KeyerUysal. (2001): The effect of pentoxifylline on intestinal ischemia/reperfusion injury. Fundam. Clin. Pharmacol., 15(1):19-22.

38. Savas, S., Delibas, N., Savas, C., Sutcu, R., and Cindas, A. Pentoxifylline reduces biochemical markers of ischemiareperfusion induced spinal cord injury in rabbits. Spinal Cord, 2002. 40(5):224-9.

39. Li, J. and Billiar, T.R. (1999):Nitric Oxide. IV. 
Determinants of nitric oxide protection and toxicity in liver. Am. J. Physiol., 276(5 Pt 1):G1069-73

40. Ranchal, I., Gonzalez, R., Lopez-Sanchez, L.M., Barrera, P.,Lopez-Cillero, P., Serrano, J., Berrardos, A., De La Mata M., Rodriquez-Ariza, A., and Muntane, J. (2006): The differential effect of PGE(1) on dgalactosamine-induced nitrosative stress and cell death in primary culture of human hepatocytes. Prostaglandins Other Lipid Mediat., 79(3-4):245-59.
41. Sass, G., Koerber, K., Bang, R., Guehring, H., and Tiegs, G. (2001):Inducible nitric oxide synthase is critical for immunemediated liver injury in mice. J. Clin. Invest., 107(4):439-47.

42. Stosic-Grujicic, S., Maksimovic, D., Badovinac, U., Samardzic, T., Trajkovic, V., Lukic, M., Mostarica-Stojkovic, M. (2001): Antidiabetogenic effect of pentoxifylline is associated with systemic and target tissue modulation of cytokines and nitric oxide production. J. Autoimmun., 16(1):47-58.

\section{التأثيرات الواقية المحتملة لمثبطات إنزيم الفسفودايستيريز ضد السمية الكبدية}

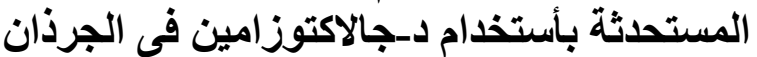

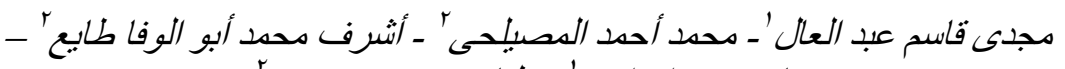

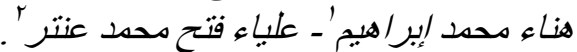

تناولت الدراسة الحالية التأثثرات الواقية المحتملة لعقار البنتوكسيفللين (كمثال لمثبطات الفوسفودايستيريز غير

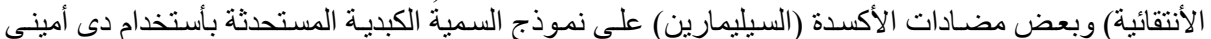

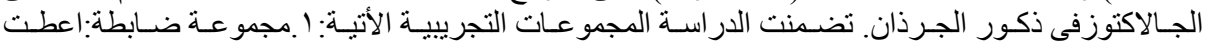

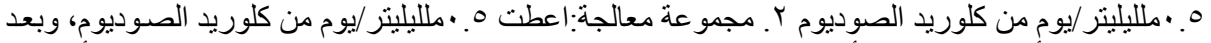

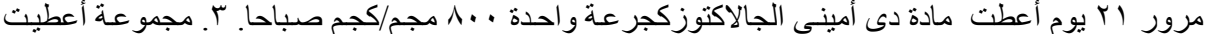

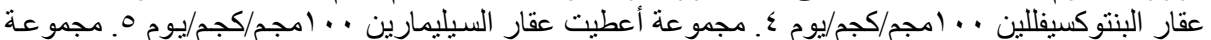

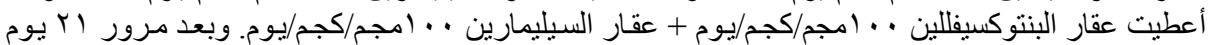

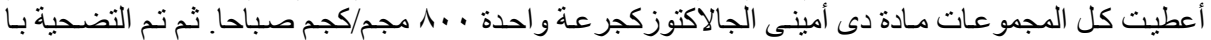

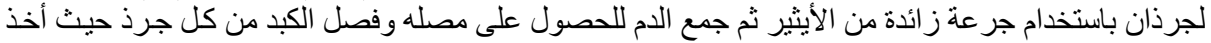

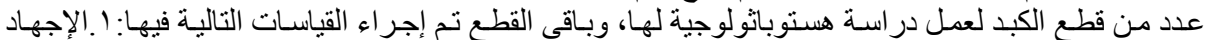

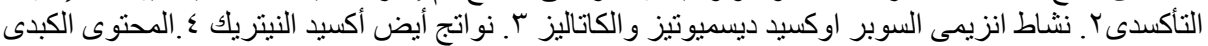

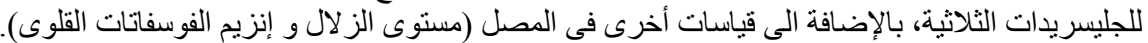

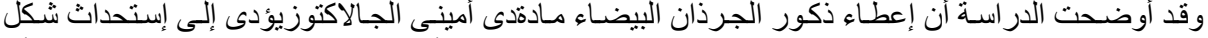

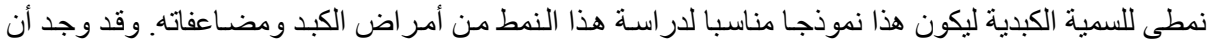

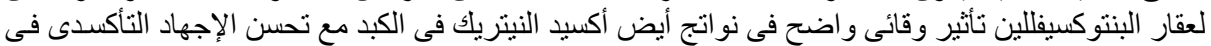

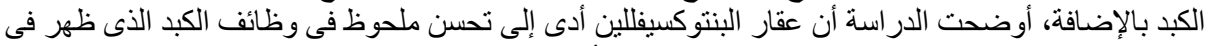
تو ازن مستوى الز لال وتحسين إنزيمات الكبد المضادة الكان للأكسدة.

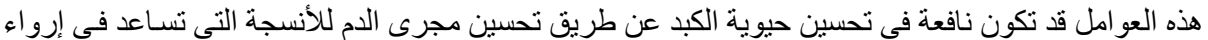

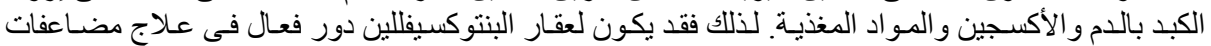

